\title{
Libraries and Computing Centers: A Blueprint for Collaboration
}

\section{Richard M. Dougherty}

Considerable attention has been focused in recent years on the uncertain relationship between academic libraries and campus computing centers. It is commonly assumed by some that one or the other will eventually become dominant on most campuses. This paper argues that the two organizations will continue to have distinct, though closely related, identities for many years. In this context they can best serve their users and institutions by establishing carefully constructed programs of collaboration that recognize both their common links in information science and their historically different missions.

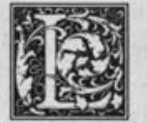

ibrarians now generally recognize the growing relationship between campus libraries and computing centers. Pat Molholt, for example, recently predicted a gradual convergence in the function of these two organizations. ${ }^{1}$ But a seldom discussed issue that both intrigues and worries people is, Will libraries be absorbed by computing centers? Interestingly enough, there are professionals from computing environments who are wondering if computing centers might be absorbed by libraries. Of course, these are questions for which there are no ready answers and that are little more than red herrings. But they do suggest the existence of unease and concern among professionals of both groups.

Questions of organizational change have been stimulated by statements such as those attributed to Richard Van Horn, chancellor of the University of Houston, who sees the computing center merging into the library, ${ }^{2}$ and Raymond Neff, vice chancellor for information technology at the University of California-Berkeley, who in a provocatively titled article, "Merging Libraries and Computer Centers: Manifest Destiny or Manifestly De- ranged," presents his rationale for why he believes the university library can be merged with the university computer center. ${ }^{3}$

The prospect of mergers may make for fascinating cocktail conversation at conferences and will certainly keep electronic mailboxes full, but speculations about mergers and absorptions only cause us to continue focusing on the wrong issues. Libraries are not going to be physically moved into computing centers, and computing centers will not find themselves housed in campus libraries. The crucial question from our point of view is, Will the library be organizationally absorbed by the computing center? Even more to the point, Will the library director report to the head of the computing center, or to the person in charge of information technology?

One way to stimulate discussion and debate is to be provocative. When Columbia University recently announced a merger of its computing center and its library under the direction of its university librarian, Patricia Battin, many in the profession breathed a sigh of relief. These same individuals also become nervous each time a report reaches the press that the librarian 
of a particular university will henceforth report to the person in charge of information technology rather than to the chief campus academic officer. The significance of such events, however, is often overblown.

"The attention of librarians and computing center professionals should not be focused on the rhetoric of mergers and takeovers but on the roles their respective organizations can play as the principal providers of information to campus communities."

The temptation to report an apparent trend toward a major organizational upheaval proved irresistible to a Chronicle reporter who wrote an article dramatically entitled "Campus Libraries Seen Threatened by Other Sources of Information."'4 Such rhetoric implies questions of interunit trust and well-defined jurisdictions between units that don't exist on most campuses. In fact, the meeting to which the reporter referred simply examined the changing roles of libraries and computing centers. In the case of Columbia University, the implication of such a headline is thoroughly misleading. Patricia Battin, in describing the changes at $\mathrm{Co}-$ lumbia, talks about the Scholarly Information Center as a philosophical construct rather than a physical entity that brings together the Columbia libraries and the computer center. ${ }^{5}$

It is important that we become more precise when we use words such as merger, $t a-$ keover, and absorption. The distinctions are not merely semantic, for if we are to avoid struggles over turf while we learn how to harness the talents and resources of libraries and computing centers, issues must be discussed accurately, frankly, and openly. And we should take care not to contribute, however unwittingly, to the dramatic inventions of outside observers.

The library's traditional mission has been to provide materials and information to all campus users, whether a freshman at a community college or a Nobel laureate at a distinguished research university. It seems only logical that librarians take full advantage of the new information tools now available because of technological advances in fulfilling this mission. It is entirely reasonable that specialists in computing centers offer their services through established research facilities on campus. The attention of librarians and computing center professionals should not be focused on the rhetoric of mergers and takeovers but on the roles their respective organizations can play as the principal providers of information to campus communities. The relationship between libraries and computing centers is changing rapidly. Soon, higher education professional will not refer to "library issues" and "computing center issues"; they will be concerned with cross-campus issues in information science that will reach the heart of the library's traditional mission.

As a visionary, Van Horn can set the tone at his university and stimulate an environment that moves his institution toward the organizational infrastructure he envisions. The necessary climate for change may already exist on his campus. While I fully subscribe to Raymond Neff's thesis that the functions of libraries and computing centers are converging, I don't conclude that organizational mergers are likely or even inevitable in the short term. Over time new organizational infrastructures will take shape, but no specific structure will be universal. Rather, the organizational structures are more likely to reflect the history, traditions, and institutional personalities of individual campuses.

Because the difference between libraries and computing centers is so great from an organizational viewpoint, I believe models that rely on coordination and collaboration are more likely to predominate in the near term than models that subordinate one unit to another. Too often, we are prone to extrapolate from personal experience or from decisions that are idiosyncratic to a specific organization. The changes that have taken place at Columbia University and Carnegie-Mellon University, for example, should not lead one to 
generalize about trends in organizational patterns. The underlying circumstances and organizational changes involving the libraries and computing centers in those cases were quite dissimilar. ${ }^{6}$

Many will recall the euphoria in the 1960 s over media, which hypnotized many educators and caused a large number of colleges and universities to combine their libraries and audiovisual centers to form new units that went by names such as "divisions of instructional media." Too often these mergers were not predicated on a well-thought-out organizational or educational philosophy. They were marriages of convenience and were often made only for the sake of fashion. In retrospect I wonder to what extent those merged units advance education, scholarship, or the role of information services. One guiding principle we should follow as we prepare our profession's future is that changes should be based on plans that enhance the educational mission of our institutions, not on the mere impression that certain redirections are, to be blunt, trendy and likely to attract attention.

A scenario, only slightly hyperbolic, will illustrate the danger of focusing too narrowly on mergers of libraries and computing centers. A merger undertaken without prior agreement of the staffs directly affected could produce some unexpected negative consequences. In the parlance of Wall Street, such an action might be characterized as a hostile takeover. Assume for a moment that the directors of a library and a computing center have been informed that their campus administration intends to reorganize the two separate units into a single campus information agency. Neither the head librarian nor the computing center director embraces the decision with enthusiasm. The staffs of the two units are even more displeased.

What options are available to those who do not want to be merged? The library staff could very well decide to seek support from another interest group in the university community: a white knight, to borrow another term from Wall Street, to save them from an undesired fate. In this instance the knight wears the robes of academic regalia. After all, many faculty do not view the current rush to "technify" with great enthusiasm. The computerization of a large campus is a multi-megabuck undertaking, and as former EDUCOM president James Emery reminds us, it is important to build a commitment to such a project among faculty. Even when philosophically in agreement with the proposition, the large costs of computerization could divert funds from projects that have a higher priority for faculty members, namely graduate student support, travel budgets, and perhaps salaries. ${ }^{7}$ A disaffected staff could play on the natural suspicions that some faculty harbor toward technology.

In using such terms as hostile takeover and white knight, I realize I may contribute to the climate I have decried in this paper, but I believe it is important to underscore the point that libraries and librarians have typically accumulated a great deal of institutional capital among their faculties, and they can easily draw upon that capital in times of stress. The absence of a commitment among library and computing center staff, in other words, could have a detrimental impact on the quality of information services that a new agency could deliver to faculty and students.

Several people asked me why I raised the spectre of staff opposition. Some think that discussing the possibility might be a selffulfillng prophecy; others simply believe that such organized opposition is unlikely. Of course there is always some risk in raising potentially contentious issues, but I have witnessed occasions when faculty opposition to a policy has brought library and university administrations to heal. Downs and McAnally, in a classic library management article in the early 1970 s, reported that the role of library directors was being affected by "hard times and inflation, changing theories of management, and technology. ${ }^{\prime 8}$

In the intervening period the stresses identified by those authors have not disappeared; in fact, most library managers would argue they have only intensified as the pace has quickened. Moreover, we know from actual experience what can happen to a library administration that decides to automate without a staff commit- 
ment. From a director's perspective, such undertakings are fraught with risk. What should be clear, based on common sense and the hard knocks of experience, is that reorganization of libraries and computing centers into divisions of information systems, if undertaken without careful advance planning, may not succeed in achieving the objective of providing highquality information services to the campus community.

Up to now I have focused on the negative aspects of the issue-namely, what strategies and behaviors to avoid-but if one agrees that the functions of libraries and computing centers are converging, the crucial question is, What can a campus administration do to build bridges that will enhance opportunities for mutually beneficial collaboration?

\section{"The staffs of both organizations must learn more about each other's professional cultures and technical vocabularies."}

Librarians have been deeply involved with library automation for almost two decades; nevertheless, there is still much we can learn from computing center professionals. At the same time, professionals from the computing center have much to learn about libraries and the services librarians deliver. Timothy Weiskel, a professor of anthropology at Yale, offers some interesting speculations on how the two organizations might adopt a strategy often observed in nature; i.e., one of behavioral mimicry or morphological imitation. Weiskel describes this process as follows:

Libraries will take on many of the capabilities of computer centers to handle electronic media and make documentation available in machinereadable form.

Computer centers . . . will begin to adopt traits traditionally characteristic of libraries. Not only will they begin to catalog, conserve and archive material in much the same way as librarians have learned to handle books in the past, but in addition the nature of their 'user-service' facili- ties is increasingly likely to match the convenient, efficient and considerate reference service we have so long enjoyed in university libraries. ${ }^{9}$

In order to stimulate a process of constructive organizational mimicry, we must first begin to establish formal working relationships at operational levels. The staffs of both organizations must learn more about each other's professional cultures and technical vocabularies. As more is learned, we might expect to see greater mutual appreciation for what each professional specialization contributes to the campus information environment.

Tom Michalak, librarian at CarnegieMellon, identifies activities that seem to be converging at his institution. First, maintaining library databases, chief among them the online catalog, in computers housed in the computing center. Second, providing access to commercial databases through gateways maintained by the computing center. Well-known sources of information such as BRS, Lockheed, and SDC are included in this category. Provision of these services requires coordination by both organizations. Third, organizing and making available numeric databases such as those organized by the Interuniversity Consortium for Political and Social Research, the library offers guides and machine-readable directories and the computing center provides consultation and software. Finally, over the next few years both organizations are likely to be involved in the general use of optical devices to store large bibliographic and nonbibliographic databases. ${ }^{10}$

In surveying the functions of computing centers and libraries on campuses today, one is struck by the simultaneous occurrence of similarities and dissimilarities. How many librarians, on a day-to-day basis, worry about computer operating systems such as UNIX or VMS or how to acquire and finance a supercomputer, or how to provide support to faculty who require heavy-duty computing power to support vector processing? But then, how many computing professionals care about bibliographic instruction, authority control of large bibliographic databases, or interpreting the structure of the literature of a discipline to a researcher? While more 
writers understandably emphasize similarities, it is also worthwhile to keep in mind that many important differences between libraries and computing centers do exist. To forget this is to invite the risk of oversimplifying the complexity of bringing about closer and better relations.

I continue to view the new information technologies as tools that librarians can use to collect, organize, store, retrieve, and disseminate information. The future roles I envision for librarians are not too dissimilar from the essential roles as they were articulated by Jesse Shera many years ago:

Knowing books and men-knowledge of the materials and their sources, and empathy with the patron and his needs-these are the twin pillars upon which library service rests. ${ }^{11}$

Fundamentally, little has changed since Shera identified the twin pillars, because providing the right book to the reader when it is needed is still the sine qua non of librarianship. But the new tools available to us are adding new levels of service. In this new environment, Battin believes that librarians will be very much involved in teaching, consulting, planning, designing, and coordinating activities related to information functions. ${ }^{12}$

What are some of the issues that a university will have to address as it shapes a campus infrastructure to facilitate and support technology-reliant, informationrich services? In addition to gaining the all-important faculty support, it will have to deal with costs of technology, pricing of information services, intellectual property rights, information acquisition policies, and lastly, growing intra-organizational dependencies.

\section{COSTS OF TECHNOLOGY}

Technology is expensive-very expensive. It is not unusual to hear price tags approaching $\$ 50$ million (or more for large campuses) when planning a fully computerized campus linked together by a telecommunications network. And institutions will find that no matter how much they buy, there will always be more information technology available than they can afford. Choices will have to be made. And in order to make intelligent choices a university community will have to reach a clear understanding of its mission and of the consequences its decisions will have on the quality of instruction and research. ${ }^{13}$

Moreover, the initial capitalization costs must be supplemented by additional high expenditures. Over the next few years university administrators will have to commit ever-growing budget allocations to maintain what is currently owned and to purchase succeeding generations of technologies. In a recent study, Martin Cummings found that it is not unusual for a research library to allocate more than \$1 million annually in direct support of computer-related activities. ${ }^{14}$ Such expenditures will become commonplace in the near future. Certainly, a university or college must be prepared to invest large sums to support its expanding technology environment. And establishing the economic base on which to build an information environment will not be a trivial issue for most campuses.

\section{PRICING OF INFORMATION SERVICES}

The manner in which institutions price information services could have a major impact on users' behavior and attitudes. The tradition of free library and information services, which have long been supported through a system of indirect subsidies (i.e., through tuition and general fund support), has had a profound impact on users' attitudes toward libraries and on the way they actually use them. In contrast, computing centers have grown up with a tradition of charging for many of their services. Raymond Neff hopes that "computing center usage for manipulating information will become a no-charge item ... following the library model." But for now, at least, libraries and computing centers operate differently, and any changes in pricing policies must be thought about very carefully.

I was never comfortable with the trend toward charging for database searching and interlibrary lending and borrowing, although I realize that no other choice may have been open to us. In the case of interli- 
brary lending, the objective was to balance lending and borrowing among institutions and to keep the volume of traffic to manageable levels. In the case of database searching, our objectives have been to (a) limit the amount of subsidy a library must commit to the activity, and (b) keep traffic at levels staff could accommodate. But by initiating charging schemes, librarians also demonstrated that users were willing to pay for information and access to materials. I would like to see direct charges to students and faculty avoided, but in light of the high cost of the new information technologies, I am not optimistic that this is possible.

\section{"The existing copyright law repre- sents a barrier to our fully exploiting the new information tools."}

Unniversity administrators are well aware of the consequences of providing library and computing center users with free goods. They assume, based on similar experiences, that there is little incentive for users to use library and information resources judiciously when services are free, but that once charges are introduced, patrons will become more selective. In view of prevailing attitudes toward information as an economic commodity, just preserving the tradition of free service for basic activities such as reference, circulation, reserves, and course-related computing may be a challenge. And given many users' apparent tolerance for paying for services, charging for specialized ones such as the creation of personalized databases or the formulation of multivariable literature searches is likely to become the norm.

\section{INTELLECTUAL PROPERTY RIGHTS}

Information technologies that allow librarians and computing center professionals the ability to store, manipulate, and disseminate bibliographic data or information in full-text electronic formats have rendered traditional copyright protections virtually meaningless. The existing copyright law represents a barrier to our fully exploiting the new information tools, and, although an eventual accommodation is likely, one should not underestimate the difficulties we face before agreements with creators, producers, and consumers of information are achieved. Authors and publishers will not relinquish easily what they believe to be their property and rights. But as professionals whose mission is to disseminate information, we must guard against agreements that could compromise our ability to do our job. Policy issues related to intellectual property must be resolved in such a way that the rights of both creators and users are protected. Librarians and their professional associations, therefore, should participate in the shaping of new copyright law. We must not take for granted that a new law would automatically preserve the rights that librarians view as central to their mission.

\section{CAMPUS INFORMATION ACQUISITION POLICIES}

Many college and university libraries have developed collection development statements that profile existing strengths of collections as well as current intensity of collecting activity. The best-known tool for this purpose is the RLG conspectus. The conspectus was devised as a way to help libraries better manage their extensive collections and help collection development managers relate print collections to those of similar libraries. The information collected during a conspectus project is also used in the formulation of interinstitutional collection development and resource sharing projects.

A great deal of progress has been made in our ability to manage print collections. But with electronic data playing everlarger roles, an institution will want to develop a campuswide policy governing the acquisition, bibliographic access, and dissemination of information in electronic formats. The absence of such a policy is likely to lead to excessive duplication of resources and inadequate knowledge and 
access to what is available. As a Columbia University database policy committee concluded,

There is no centralization of information about databases in the University. Nor is there uniformity of access to or support for these databases. This has led to duplication of effort in some cases and to barriers to the use of scholarly information in others. ${ }^{16}$

\section{ORGANIZATIONAL DEPENDENCIES}

Until recently, libraries and computing centers could operate virtually independently without fear of disturbing each other. The growing convergence and overlap of activities, however, has begun to blur the boundaries between the two units and in turn to create interunit dependencies, as simple illustrations make clear. If the computing center manages the campus telecommunications system and the computer on which the library's online catalog resides, the library is dependent on the performance of the computing center for the quality of its services. At the same time, the most visible and widely used product a computing center can distribute to users through its telecommunications network will be the library's cata$\log$. Both units, in other words, are associated with the quality of the product delivered and are therefore mutually dependent.

The growing use of information technologies by students and faculties will create a broad series of dependencies across the campuses, and not just between libraries and computing centers. It will be important that campus policy makers take steps to prevent units and individuals from building technological railroads of different gauges. On large campuses, it is not uncommon to find several distinct networks not linked by an overarching network that allow users to work among the systems. Before a campuswide network can become a reality, though, a series of gateways between such disparate networks must be created. This linking of systems and users into an affordable, unifying network may become one of the most difficult challenges facing campus officials.

\section{DEVELOPING A CAMPUS STRATEGY}

The convergence of library and computing center activities is an issue from which no sector of the campus community is exempt. Creating a coordinated campus network will require careful planning, hard choices, and a new set of underlying assumptions and policies governing the provision of information services.

Many campus constituencies will have a stake in the new network environment, but stakeholders will not view the new environment with equal enthusiasm. The greatest challenge to campus planners is to create circumstances in which all parties feel they have benefited, a classic win-win outcome. We want all parties to feel they have gained in status and career enhancement. A friend and former mentor, at a time when we were trying to convince a group of skeptical faculty and librarians to adopt a course of action some opposed, counseled, "if all else fails, maybe a little bribery will do the trick." In more polite terms, what is needed is a set of incentives that can be strategically employed to create the necessary environment.

\section{"Technology is giving us the oppor- tunity to reshape the way scholarship is conducted."}

As for fostering constructive and enduring relations between libraries and computing centers, many actions can be taken almost immediately. For example, joint working groups could begin to wrestle with issues of common concern. The development and maintenance of databases; the acquistion, bibliographic control, and distribution of software; and the securing of literary property rights are but three examples. In addition to closely examining such issues, these joint working groups could provide opportunities for professionals with distinctly different organiza- 
tional cultures to learn more about each other, which is crucial if these two groups are to ever build bonds of mutual respect for their unique roles.

Society has entered the information age, and the future of many professions and occupations is very uncertain, but information has been and continues to be our business. To paraphrase a recent Wall Street Journal ad, "Information is not power, where to find it is." Ours is a profession with a future if only we will seize the opportunity. And, in my judgment, we can enhance our opportunities even further by joining forces with professionals from the computing world.

Technology is giving us the opportunity to reshape the way scholarship is conducted. In a technologically oriented environment, scholars will have ready access to a wide variety of discipline-oriented databases and the contents of library catalogs plus the capabilities of reaching from a single terminal many databases and compiling personal files of bibliographical information. They will soon be able to create personal stores of articles, reprints, electronic messages from colleagues, and numerical data sets-unique collections that will generate thinking and research in rich and productive ways. These exciting developments should stimulate anyone in the business of storing and providing information to search for new avenues of cooperation and collaboration.

The campus information environment envisioned by Van Horn is exciting. The manifest destiny projected by Neff is manifestly not "deranged." Librarians and computing center professionals will find, if they take the opportunity, that they are natural allies. Both have special and complementary skills that are in short supply. Working together, they should become a powerful influence in the reshaping of research and scholarship in higher education.

\section{REFERENCES}

1. Pat Molholt, "On Converging Paths: The Computing Center and the Library," The Journal of Academic Librarianship 11:284-88 (Nov. 1985).

2. See reference to Van Horn in M. Mitchell Waldrop, "Personal Computers on Campus," Science 228:438 (Apr. 26, 1985).

3. Raymond K. Neff, "Merging Libraries and Computer Centers: Manifest Destiny or Manifestly Deranged," EDUCOM Bulletin 20:8-12, 16 (Winter 1985).

4. Judith Axler Turner, "Campus Libraries Seen Threatened by Other Sources of Information," The Chronicle of Higher Education (Dec. 4, 1985), p.30-31.

5. Patricia Battin, "Crossing the Border: Librarianship in the Information Age," The Haroard Librarian 19:9 (Sept. 1985).

6. For a view from Carnegie-Mellon see Thomas Michalak, "Libraries and the Information Revolution," CMU Libraries' News Resources, no.5 (Mar. 1986) (special issue).

7. James C. Emery, "Issues in Building an Information Technology Strategy," EDUCOM Bulletin 19:8 (Fall 1984).

8. Arthur M. McAnally and Robert B. Downs, "The Changing Role of Directors of University Libraries," College \& Research Libraries 34:103-25 (Mar. 1973).

9. Timothy C. Weiskel, "Libraries as Life-Systems: Information, Entropy, and Coevolution on Campus," College \& Research Libraries 47:554 (Nov. 1986).

10. Michalak, "Libraries and the Information Revolution."

11. Jesse H. Shera, Introduction to Library Science (Littleton, Colo: Libraries Unlimited, 1976) p.64.

12. Battin, "Crossing the Border," p.10.

13. See Battin for further discussion of these points.

14. Martin H. Cummings, "The Impact of New Technologies on Library Services," Proceedings of the 5th Annual Meeting of the Society for Scholarly Publishing.

15. Neff, "Merging Libraries and Computer Centers," p.9.

16. Columbia University, Final Report of the Columbia University Database Policy Committee (New York: Columbia University, 1985), p.1. 